\title{
Transitioning to the workforce - resilience building workshop for pharmacy interns
}

\author{
Andrew D. Bartlett (D), Jocelyn Bussing, Simmie Chung, Irene S. Um \\ The University of Sydney, School of Pharmacy, Faculty of Medicine and Health, Sydney, NSW, Australia
}

\author{
Keywords \\ Internship \\ Pharmacy Intern \\ Resilience \\ Transition \\ Workforce
Correspondence
DrIrene Um
School of Pharmacy
Faculty of Medicine and Health
Science Rd
The University of Sydney
NSW 2006 \\ irene.um@sydney.edu.au
}

\begin{abstract}
Introduction: This short report describes the piloting of a resilience building workshop for pharmacy interns to aid with the transition from university to the workforce. Methods: A 2-hour workshop was designed focussing on responding to change and exploration of real-life examples that interns had encountered in the workplace. The workshop involved a combination of whole and small group discussions, problem-solving and self-reflection. A total of 108 interns participated in the workshop as part of The University of Sydney Pharmacy Intern Training Program. Conclusion: Pharmacy educators must continue to embed resilience training in curricula to promote graduates' readiness to transition and deal with adversity in the contemporary workforce.
\end{abstract}

\section{Introduction}

It is widely recognised that the transition from being a student to an independent health professional in the workforce is a challenging and stressful time. This period involves intense learning and change as the novice is socialised into their new workplace environment. Problems such as burnout, relocation for a job, lack of direction, poor job satisfaction and high staff turnover are some of the common themes reported in the literature for graduate health professionals (Mak et al., 2013; Kennedy et al., 2015; Magola et al., 2018). Factors contributing to this experience may be the gap between graduates' expectations and reality (Jewell, 2013). According to Duchscher, new graduates are confronted with "transition shock", which represents the initial reaction of emotional, physical, socio-cultural and developmental, and intellectual changes (Duchscher, 2009). In addition, concerns about excessive workloads, variable organisational and professional support, and negative workplace cultures are commonly cited by new health graduates.
The importance of resilience training is emerging in response to increasing evidence of stress and burnout in health professionals. Higher resilience levels are associated with lower levels of burnout and better tolerance of general and clinical uncertainty (Cooke et al., 2013). A scoping review about resilience in the context of pre-qualifying health education defined resilience as "the dynamic capacity to overcome adversity, drawing on personal, social and organisational resources, to achieve personal growth and transformation" (Sanderson \& Brewer, 2017; p: 69). This review also found nine studies describing innovative approaches to enhancing resilience, mostly in medicine and nursing. The strongest evidence is for using resilience workshops and cognitive behavioural interventions, with some evidence for small group problem solving (Rogers, 2016). In university learning contexts, it is recommended for health students to be engaged in identity building work, capacity and strengths development, and learning leadership for change (McAllister \& McKinnon, 2009). 
In Australia, pharmacy graduates are required to complete an internship or pre-registration training that involves approximately a year of supervised practice in the workplace and are commonly referred to as interns. A national wellbeing survey conducted in 2016-2017 in Australia revealed that pharmacy graduates entering the workplace for the first time are mostly unprepared to deal with stress-related issues in their workplaces (Chapman et al., 2020). A cross-sectional survey of pharmacy interns in Australia found a mismatch between expectations and experiences, and $45 \%$ of respondents agreed/strongly agreed that they wanted to do something else other than being a practising pharmacy by the end of the internship (Mak et al., 2013). Dissatisfaction due to unrealistic expectations may cause these pharmacy graduates to leave the profession (Mak et al., 2013).

Early career training has been articulated as a development goal by the International Pharmaceutical Federation (FIP), recognising its importance in transforming the global pharmacy workforce (International Pharmaceutical Federation (FIP), 2020a). Further, leadership and self-regulation are identified as a competency domain with supporting behavioural statements in the FIP Global Competency Framework version 2 designed to support early-career training (International Pharmaceutical Federation (FIP), 2020b).

Therefore, the University of Sydney in Australia elected to introduce a workshop called 'Transitioning into the workplace' in the curriculum for interns as part of its Pharmacy Intern Training Program. The programme is a blended course of face-to-face and online teaching designed to complement experiential workplace learning. The aim of this pilot workshop was to help pharmacy interns recognise how they respond to change and develop coping strategies for dealing with change, to aid with the transition from university to the workforce.

\section{Description and development of workshop}

The workshop was developed by four school members with expertise in management, leadership and intern training. The University of Sydney library database was initially searched using the key terms transition, workforce, and health professionals. Three relevant articles were identified that discussed issues faced by health professional graduates as they transition to the workforce in nursing, paramedics and pharmacy. The existing literature and anecdotal feedback informed the learning outcomes and contents of the workshop. As part of the undergraduate programme, final year pharmacy students undertake a management unit that covers principles and skills of effective leadership and problem-solving. The workshop was designed to build on pharmacy graduates' existing knowledge and competencies relating to self-leadership and reflective skills, as well as applying a problem-solving framework to real-world examples that they had encountered in the workplace during their supervised practice.

For pre-work, interns were provided with some resources one week prior to the workshop to complete, which included background reading and a self-reflection mindset assessment quiz. A variety of learning activities, including whole and small group discussion and reflection, were used to achieve the learning outcomes for the workshop. During the workshop, interns were asked to consider their learning styles (Honey \& Mumford, 1982) and approach to change. Interns were encouraged to employ some practical resilience-building tools such as gratitude diaries, mindfulness and practical empathy for a 21-day period. A two-week intervention demonstrated the benefits of gratitude and kindness in reducing anxiety and building optimism and satisfaction with life, all key factors in building resilience (Kerr et al., 2015). The learning outcomes and lesson plans for the workshop are provided in Tables I and II. Each intern was provided with a hard copy worksheet to guide them through the self-reflection and small group activities.

Table I: Learning outcomes of the 'Transitioning into the workplace' workshop mapped to competency standards and behaviours

\begin{tabular}{|c|c|c|}
\hline Learning outcomes & Enabling competencies* & Behaviourst \\
\hline Recognise emotions in self and others, and apply emotional intelligence in face of change & 1.1.4, 4.1.1, 4.1.2, 4.1.3 & $4.5 .6,4.5 .7,4.5 .8$ \\
\hline Apply coping strategies for managing change, including stress management tools & $1.1 .4,1.1 .5,4.1 .1,4.1 .2,4.1 .3$ & 4.5.7, 4.5.8 \\
\hline Apply problem-solving skills to potential conflict and issues arising in the workplace & $1.1 .4,1.1 .5,1.5 .2,2.4 .1,2.4 .2$ & 3.2.1, 4.4.4, 4.5.7, 4.5.8 \\
\hline $\begin{array}{l}\text { Engage in reflection and take appropriate actions including self-regulation and seek support } \\
\text { when necessary }\end{array}$ & $1.1 .4,1.4 .1,1.4 .2,4.1 .2$ & $4.2 .7,4.2 .8,4.2 .9,4.5 .8$ \\
\hline
\end{tabular}

*From the National Competency Standards Framework for Pharmacists in Australia 2016 (Pharmaceutical Society of Australia, 2016)

†From the FIP Global Competency Framework Version 2 (International Pharmaceutical Federation (FIP), 2020b) 
Table II: 'Transitioning into the workplace' workshop lesson plan

\begin{tabular}{|c|c|c|}
\hline Order and description of activities & Duration & Type of activity \\
\hline $\begin{array}{l}\text { 1. Introduction and recap } \\
\text { The facilitator outlined the purpose and learning outcomes of the workshop, } \\
\text { and then provided a didactic summary of key concepts including fixed and } \\
\text { growth mindset (Dweck, 2017); system } 1 \text { and } 2 \text { thinking (Kahneman, 2013) and } \\
\text { stress management tools for building resilience such as gratitude, empathy, and } \\
\text { mindfulness (The Resilience Project, 2020). }\end{array}$ & 15 minutes & $\begin{array}{l}\text { Didactic presentation delivered to the } \\
\text { whole group }\end{array}$ \\
\hline $\begin{array}{l}\text { 2. Learning styles and problem solving } \\
\text { The facilitator divided the room into four quadrants and described the } \\
\text { attributes of four learning style approaches: activist, theorist, pragmatist and } \\
\text { reflector (Honey \& Mumford, 1982). Interns then moved into the relevant } \\
\text { quadrant that best described their natural learning style. In pairs, interns shared } \\
\text { a recent example of solving a problem in the workplace and how they applied } \\
\text { the attributes of their learning style. }\end{array}$ & 15 minutes & Self-reflection, sharing in pairs \\
\hline $\begin{array}{l}\text { 3. Recent encounter or relationship in the workplace } \\
\text { Interns were asked to self-reflect on a recent encounter or relationship. They } \\
\text { shared their examples in their small groups, considering the following aspects } \\
\text { of problem/conflict, potential error and ethical dilemma. They then discussed } \\
\text { strategies, solutions and alternate pathways. The whole group discussion was } \\
\text { facilitated with each small group contributing salient points. }\end{array}$ & 40 minutes & $\begin{array}{l}\text { Self-reflection, small group problem- } \\
\text { solving and discussion, whole group } \\
\text { discussion }\end{array}$ \\
\hline $\begin{array}{l}\text { 4. Task/process that is new or different in the workplace } \\
\text { Interns were asked to self-reflect on a task/process that was new or different in } \\
\text { the workplace. They shared their examples in their small groups, considering } \\
\text { the following aspects of problem/conflict, potential error and ethical dilemma. } \\
\text { They then discussed strategies, solutions and alternate pathways. Whole group } \\
\text { discussion was facilitated with each small group contributing salient points. }\end{array}$ & 40 minutes & $\begin{array}{l}\text { Self-reflection, small group problem- } \\
\text { solving and discussion, whole group } \\
\text { discussion }\end{array}$ \\
\hline $\begin{array}{l}\text { 5. Wrap up } \\
\text { The facilitator summarised the key points from the workshop, provided } \\
\text { information about accessing counselling and support services, and closed the } \\
\text { workshop. The facilitator encouraged interns to employ practical resilience- } \\
\text { building tools post-workshop. }\end{array}$ & 10 minutes & $\begin{array}{l}\text { Didactic presentation delivered to whole } \\
\text { group }\end{array}$ \\
\hline
\end{tabular}

\section{Lessons learned and future plans}

The two-hour workshop was compulsory for all interns enrolled in the University of Sydney Pharmacy Intern Training Program and was piloted in February 2020. The workshop was delivered by one facilitator to a group of 36 interns per session. In total, 108 interns participated in the workshop.

Anecdotal feedback from interns who participated in the workshops was generally favourable, highlighting the relevance and value, indicating the applicability in their early experiences. School members intentionally piloted the workshop at the start of the year, where most interns had only just started their supervised practice for approximately one month. Educators could introduce the workshop after at least three months of training, which would allow for more practical experience and relevance. While no formal evaluation for the workshop was conducted, as part of the university's standard operations, interns were asked to complete an anonymous questionnaire about the course. Here, some had provided written feedback, including they found it "useful" and that it provided "strong support from the outset with reinforcement and encouragement". In the future, a more comprehensive evaluation should be conducted.

Although the workshop was piloted successfully, the authors recognise that stand-alone training only constitutes a small part of the bigger picture. A more considered and constructively aligned approach throughout pharmacy education curricula, starting at the undergraduate level to equip pharmacy graduates to cope with the transition to the workforce, is recommended.

\section{References}

Chapman, C. B., Wilson, S. G., Wilson, D. I., \& Dunkley, M. K. (2020). National survey of pharmacists, intern pharmacists and pharmacy students in Australia: the nature and extent of stress and wellbeing. The International Journal of Pharmacy Practice. https://doi.org/10.1111/ijpp.12604 
Cooke, G. P. E., Doust, J. A., \& Steele, M. C. (2013). A survey of resilience, burnout, and tolerance of uncertainty in Australian general practice registrars. BMC Medical Education, 13, 2. https://doi.org/10.1186/1472-6920-13-2

Duchscher, J. E. B. (2009). Transition shock: The initial stage of role adaptation for newly graduated Registered Nurses. Journal of Advanced Nursing, 65(5), 1103-1113. https://doi.org/10.1111/j.1365-2648.2008.04898.x

Dweck, C. S. (2017). Mindset. London: Robinson. Honey, P., \& Mumford, A. (1982). The Manual of Learning Styles. Maidenhead: Peter Honey

International Pharmaceutical Federation (FIP). (2020a). The FIP Development Goals: Transforming global pharmacy

International Pharmaceutical Federation (FIP). (2020b). FIP Global Competency Framework Version 2: Supporting the development of foundation and early career pharmacists

Jewell, A. (2013). Supporting the novice nurse to fly: a literature review. Nurse Education in Practice, 13(4), 323327. https://doi.org/10.1016/j.nepr.2013.04.006

Kahneman, D. (2013). Thinking, fast and slow (1st pbk. e). New York: Farrar, Straus and Giroux

Kennedy, S., Kenny, A., \& O'Meara, P. (2015). Student paramedic experience of transition into the workforce: $A$ scoping review. Nurse Education Today, 35(10), 1037-1043. https://doi.org/10.1016/j.nedt.2015.04.015

Kerr, S. L., O'Donovan, A., \& Pepping, C. A. (2015). Can Gratitude and Kindness Interventions Enhance Well-Being in a Clinical Sample? Journal of Happiness Studies, 16(1), 17-36. https://doi.org/10.1007/s10902-013-9492-1

Magola, E., Willis, S. C., \& Schafheutle, E. I. (2018). What can community pharmacy learn from the experiences of transition to practice for novice doctors and nurses? A narrative review. International Journal of Pharmacy Practice, 26(1), 4-15. https://doi.org/10.1111/ijpp.12349

Mak, V., March, G., Clark, A., \& Gilbert. (2013). Australian intern pharmacists\&rsquo; perceived preparedness for practice, and their expectations and experiences of the internship year and future career intentions. Integrated Pharmacy Research and Practice, 25. https://doi.org/10.2147/IPRP.S50387

McAllister, M., \& McKinnon, J. (2009). The importance of teaching and learning resilience in the health disciplines: $A$ critical review of the literature. Nurse Education Today, 29(4), 371-379.https://doi.org/10.1016/j.nedt.2008.10.011

Pharmaceutical Society of Australia. (2016). National Competency Standards Framework for Pharmacists in Australia

Rogers, D. (2016). Which educational interventions improve healthcare professionals' resilience? Medical Teacher, 38(12), 1236-1241. https://doi.org/10.1080/0142159X.2016.1210111

Sanderson, B., \& Brewer, M. (2017). What do we know about student resilience in health professional education? A scoping review of the literature. Nurse Education Today, 58, 65-71. https://doi.org/10.1016/j.nedt.2017.07.018
The Resilience Project. (2020). The Resilience Project. Retrieved June 27, 2020, from https://theresilienceproject.com.au/ 